\title{
Bioconversion of Lignocellulosic Agriculture Waste to an Edible Mushroom, the Functional Food for Healthy Life During Covid 19
}

\author{
Iwan Saskiawan*, Atik Retnowati \\ Research Center for Biology, , Indonesian Institute of Sciences, Jl. Raya Jakarta Bogor Km. 46 Cibinong 16911, \\ Indonesia \\ *Corresponding author. Email: iwansaskiawan@gmail.com
}

\begin{abstract}
Production of lignocellulosic biomass is routinely generated by agro-industrial activities in Indonesia. Those materials are disposed of in the environment without any treatment leading to serious environmental pollution problems. These agricultural wastes can be potentially bio converted into edible mushroom cultivation, known as a superfood because of their nutritional value and their function as a functional food. A mushroom is defined as fungi that can be a distinctive fruiting body, either epigeous or hypogeous. Oyster mushroom (Pleurotus ostreatus) and rice straw mushroom (Volvariella volvacea) are two kinds of mushrooms popular in Indonesia. Oyster mushroom is cultivated using sawdust as the main substrate and rice straw mushroom is cultivated using rice straw as the main substrate. This paper revealed the method of oyster and rice straw mushroom cultivation in Indonesia using both main substrates, sawdust, and rice straw. The biological character and bioconversion of lignocellulose substrate into the fresh fruiting body of mushrooms is expressed in Biological Efficiency (BE). It was determined by the weight of fresh mushrooms as a percentage of the weight of the wet substrate. The result shows that the BE of P. ostreatus growing on sawdust was 35-40\%, while $V$. volvacea growing on rice straw was $20-25 \%$. In addition, this study concluded that the cultivation technology of those two kinds of popular edible mushrooms in Indonesia has been done in a modest method that has the better prospect for developing on a larger scale. The mushroom as a functional food will also be discussed in this paper by reviewing some related publications.
\end{abstract}

Keywords: Bioconversion, Lignocellulose, Mushroom cultivation, Pleurotus ostreatus, Valvariella volvacea.

\section{INTRODUCTION}

The agricultural sector is one of the national development programs in Indonesia. As a result, huge amounts of agricultural waste which are rich in lignocellulosic compounds are routinely produced. Handling and disposal of those are often problematic due to their chemical structure and decomposition properties. Dumping or burning them in the surrounding environment will lead to environmental pollution and cause health hazards [1]. One of the potential uses in applying agricultural wastes is for growing various edible mushrooms in Indonesia. The Ministry of Agriculture of Republic Indonesia has prioritized the development of six kinds of mushroom cultivation which have an economic value, such as rice straw mushroom (Volvariella volvacea), oyster mushrooms (Pleurotus ostreatus), ear mushroom (Auricularia spp.), champignon (Agaricus bisporus), lingzhi (Ganoderma spp.), and shiitake (Lentinula edodes). The Research Centre for Biology, Indonesian Institute of Sciences also develops and investigates the biological and cultivation aspects of many kinds of edible mushrooms.

A mushroom is defined as the fungus that has a distinctive fruiting body which can be either epigeous or hypogeous. The fruiting body is large enough to be seen by the naked eye and to be picked up by hand [2]. Taxonomically, mushrooms belong to the Kingdom of Fungi, a group very distinct from plants, animals, protista, and monera [3]. Furthermore, mushrooms are different from other heterotrophic organisms in the way they intake food to the cell. They do not have chlorophyll and they do not produce their "food" by the 
photosynthesis process, but they obtain it by absorbing it into their cells.

The number of fungi species in the world was about 1.500.000 that comprised micro and macro fungi [4]. About 25 years later, there was fungal diversity revisited: 2.2-3.8 million species with about 120,000 currently described species or about $8 \%$ of the number fungal diversity [5]. The increasing number of those species is caused by the increasing use of molecular approaches in many areas of fungal studies. The species number in tropical and temperate countries is still questionable. Tropical countries, such as Indonesia, are definitely fungal species-rich compared to temperate countries. Retnowati et al. [7] calculated 2.273 species reported from Indonesia, particularly from 7 major areas: Java, Sumatra, Kalimantan, Sulawesi, Indonesian part of Papua New Guinea, Moluccas, and Lesser Sunda Island. There are still thousands of undescribed species from Indonesia that need to be explored.

Nowadays mushroom cultivation has become a very attractive activity in the agriculture sector, because the growing mushroom is simple and it needs a short harvesting period compared to the other agriculture commodities. Based on the materials of mushroom cultivation, Saskiawan and Hasanah [8] reported that there are two substrate categories used in mushroom production in Indonesia. The first category is using rice straw as the main substrate. Mushrooms cultivated in this substrate are rice straw mushroom ( $V$. volvacea), and champignon (A. bisporus). The second category is using sawdust added by some sugar palm waste, banana leaf, coconut fiber, corn cob. Mushrooms cultivated in those substrates are an oyster mushroom ( $P$. ostreatus), ear mushroom (Auricularia sp.), shiitake (L. edodes), and Lingzhi (Ganoderma sp.)

The purpose of this study is to describe the cultivation technology of two kinds of popular mushrooms in Indonesia, rice straw mushroom ( $V$. volvacea) using rice straw as a substrate and oyster mushroom ( $P$. ostreatus) using sawdust as a substrate. In addition, these two mushrooms are of commercial importance in Indonesia.

\section{MATERIALS AND METHOD}

\subsection{Preparation of Spawn}

The culture of $V$. volvacea and $P$. ostreatus was obtained from the Research Center for Biology, Indonesian Institute of Sciences and it is maintained on a Potato Dextrose Agar (PDA) slant. Two types of mushroom spawn developed in this study are the mother spawn and the planting spawn. The mother spawn was made up of sorghum for $V$. volvacea and broken corn for Pleurotus sp. with the addition of $2 \%$ lime $\left(\mathrm{CaCO}_{3}\right)$. Then, it was put into a bottle and sterilized in an autoclave at $121{ }^{\circ} \mathrm{C}, 1 \mathrm{~atm}$ for 20 minutes [9]. After sterilization, each bottle was inoculated with an agar disk of $6 \mathrm{~mm}$ diameter containing mycelium of the culture of mushroom, and then incubated at $30^{\circ} \mathrm{C}$ in the absence of light for a 15-days period. Materials used for planting spawn substrate for $V$. volvacea are horse manure (42\%), cotton waste $(42 \%)$, chopped straw $(11 \%)$, rice bran (2\%), and lime (3\%). Meanwhile, materials used for planting spawn for Pleurotus sp. are sawdust (73\%), rice brand $(25 \%)$ lime $(2 \%)$, and gypsum (1\%). After composting for 1 week, the substratum is filled into a plastic bag $(15 \times 25 \mathrm{~cm})$ and autoclaved. The substrate was continued by inoculating the mother spawn after cooling down.

\subsection{Cultivation of $V$. volvacea}

Cultivation of $V$. volvacea, Rice Straw Mushroom (RSM), was done by using rice straw which is the main substrate used for growing this mushroom. The cultivation method applied in this research was a semiintensive method. A mushroom house for growing V. volvacea was covered with plastic sheets stretched over bamboo frames. Recently, RSM growers use styrofoam instead of bamboo mats. The size of the mushroom house is about $7 \mathrm{~m}$ in length, $4 \mathrm{~m}$ in width and $5 \mathrm{~m}$ in height. It is also equipped with a $1 \mathrm{~m} \times 0.5 \mathrm{~m}$ window in the back and the front side of the mushroom house. The house usually has two tiers of shelves, each of them has five layers. The total bed area is about $69 \mathrm{~m}^{2}$.

Rice straw (70\%), cotton waste or kapok waste (20\%) are the raw materials for bedding with a total weight of about $1000 \mathrm{~kg}$. These raw materials are mixed with $8 \%$ rice bran and $2 \%$ lime and then composted for six days with two turns. The substrate then was filled up on the shelves. Once ready, the mushroom house has to be pasteurized using water steam maintained at the temperature of $65-70{ }^{\circ} \mathrm{C}$ for 7 hours [7]. The inoculation of spawn was commonly done when the temperature in the house was developed best at a temperature $33-35^{\circ} \mathrm{C}$. Once the spawn has been finished, the house is tightly enclosed for 6 days. On the seventh day proper ventilation is provided and a small amount of water can be introduced onto the beds to maintain temperature and humidity in the house as well as in the substrate. Under these conditions, the fruiting body usually can be developed 9-10 days after spawning. The fruit body will be harvested for 14-18 days. [7]

\subsection{Cultivation of P. ostreatus}

The main substrate in $P$. ostreatus cultivation which is generally used is sawdust as the prime ingredients and the addition of $\mathrm{CaCO}_{3}(2 \%), \mathrm{CaSO}_{4}(2 \%)$, rice bran $(15 \%)$ and corn flour (4\%). The phase I composting is done by mixing the sawdust and $\mathrm{CaCO}_{3}$ for 5 days. Then, normally the other materials were added and mixed properly. 
Watering was done to obtain a moisture content range from 70 to $75 \%$. Polypropylene bags $(18 \times 35 \mathrm{~cm})$ were filled with $1.0 \mathrm{~kg}$ of the substrate, sterilized at $120{ }^{\circ} \mathrm{C}$ for 20 minutes. The sterilized bags then allowed to cool down to the desired inoculation temperature. Once the bags were sterilized, the spawns were inoculated with at a rate of $5 \%$ of the substrate weight, and incubated in an incubation room maintained at $28 \pm 5{ }^{\circ} \mathrm{C}$ and the relative humidity is kept at 70-75 $\pm 5 \%$. After the substrate was fully colonized, the next step in this phase is locating the bags in a growing room and incubating them at $25 \pm 5^{\circ} \mathrm{C}$ at a relative humidity of $80-85 \pm 5 \%$. In the growing room, the bags were opened. Harvestable mushrooms appear 7 to 10 days after opening the bag. Harvesting was done by grasping the stipe and gently pulling or twisting the fruiting body from the substrate [8].

\subsection{Determination of Productivity and Other Parameters}

The productivity of mushroom production is considered to be dependent upon mushroom yield, the number of fresh mushrooms produced in a specific substrate. Biological efficiency (BE) is a simple way to calculate the effectiveness of a mushroom to convert the substrate to be a fruit body. The biological efficiency is the ratio of the weight of the fresh fruiting body $(\mathrm{kg})$ per fresh weight of substrate $(\mathrm{kg})$, expressed as a percentage.

\section{RESULTS AND DISCUSSIONS}

\subsection{Cultivation of $V$. volvacea}

Nowadays, mushroom houses for growing straw mushrooms in Indonesia are constructed using Cold Form Steel (CFS) instead of using bamboo. The reasons are the CFS construction is more durable than using bamboo construction as well as the bamboo is recently difficult to find especially in urban areas (Figure 1.a and b). The mushroom housing could be made from local materials, and in this experiment we used polypropylene plastic as covered sheets and layered by styrofoam to provide required temperature and humidity during the growth of the straw mushroom (Figure 1.c).

The temperatures in the compost substrate can reach $79.8^{\circ} \mathrm{C}$, as the highest on day 4 . Then it was decreased up to $59.6{ }^{\circ} \mathrm{C}$ on the day 6 of the composting process. Furthermore, the highest $\mathrm{pH}$ of 7.6 was obtained on the day of 4 and the $\mathrm{pH}$ was 7.2 at the end of the composting process (Table 1). The purpose of the composting process is to develop the nutrient source required by the growth of mushrooms. The nutrients are provided in the substrate as well as physical condition to support the growth of mushroom.

Table 1. The temperature and $\mathrm{pH}$ of the substrate for $V$. volvacea during composting process

\begin{tabular}{ccccccc}
\hline Physical & \multicolumn{6}{c}{ The day of composting } \\
\cline { 2 - 7 } Characters & $1^{\text {st }}$ & $2^{\text {nd }}$ & $3^{\text {rd }}$ & $4^{\text {th }}$ & $5^{\text {th }}$ & $6^{\text {th }}$ \\
\hline $\begin{array}{c}\text { Temperature } \\
\left({ }^{\circ} \mathrm{C}\right)\end{array}$ & 59.6 & 65.8 & 75.2 & 79.8 & 71.2 & 59.6 \\
\hline $\mathrm{pH}$ & 6.3 & 6.8 & 7.0 & 7.6 & 7.3 & 7.2 \\
\hline
\end{tabular}

Zikriyani et al. [10] reported that RSM is considered as one of the popular and the easiest mushrooms to be cultivated because of its short production cycle [9]. This species grows in warm weather, throughout tropic and subtropic regions. The RSM's mycelial growth is in optimal temperature at 30 to $35^{\circ} \mathrm{C}$, and at 28 to $30{ }^{\circ} \mathrm{C}$ for its fruiting body production [10]. Generally, the optimal temperature for growing mushrooms is at 25 to $40{ }^{\circ} \mathrm{C}$ with the optimum temperature at $35{ }^{\circ} \mathrm{C}$ [11]. Furthermore, relative humidity in the range of from 70 to $90 \%$ is the best for RSM growth [12]. The pH optimal for growing of RSM is $6.5-7.0$ [13].

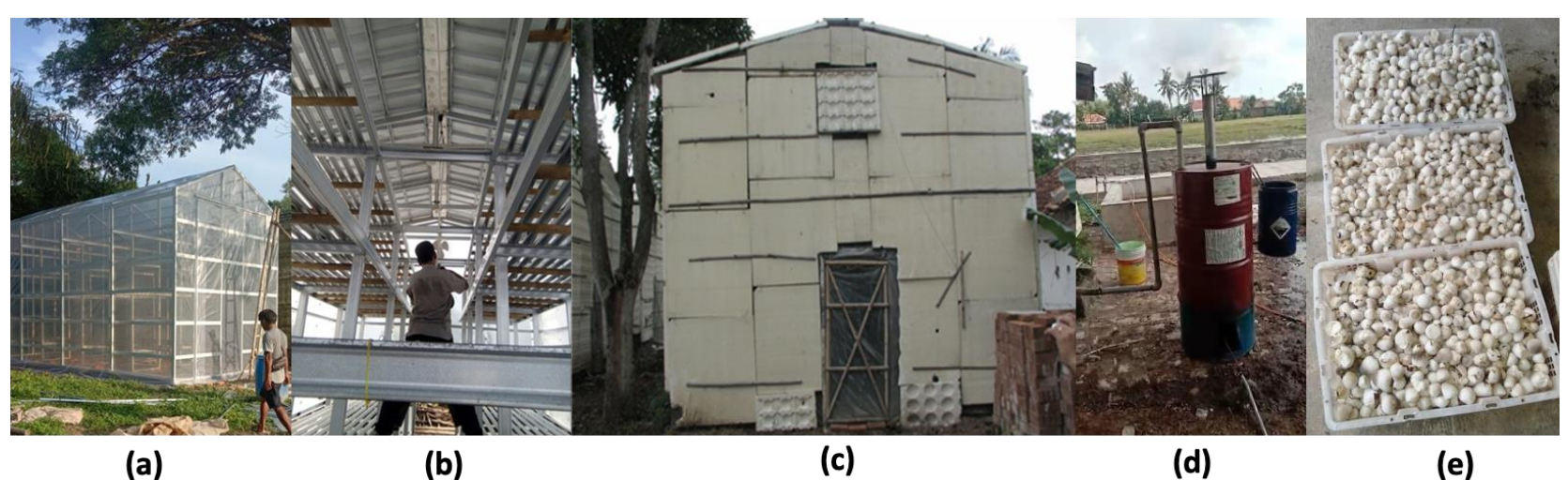

Figure 1. Cultivation of $V$. volvacea or rice straw mushroom (RSM): (a) mushroom house building process; (b) helve RSM for cultivation; (c) styrofoam as the outer layer of mushroom house; (d) steamer for pasteurizing the RSM substrate at the mushroom house; (e) ready to sell RSM fruiting bodies in the container. 
The pasteurization process was done by flowing the water steam into the mushroom house through the pipe (Figure 1.d). This process was carried out until the room temperature reached $70-75{ }^{\circ} \mathrm{C}$ for 4 hours. The temperature has cooled overnight to make an optimal condition for growing the rice straw mushroom. It took place at $33-34{ }^{\circ} \mathrm{C}$ and the spawn was inoculated on the medium. To support the mycelial proliferation of spawn, the temperature and humidity in the mushroom house should be kept at $33-35{ }^{\circ} \mathrm{C}$ and $80-90 \%$ with no ventilation and dark condition. A complete run of mycelium to colonize the substrate took 9 to 10 days after spawning. Then, the production of the fruiting body would be achieved in about 14 to 15 days. The mushroom house temperature and humidity are important factors that maintain the production of a fruiting body. It was done by regularly sprinkling clean water on the floor of the mushroom house.

The production of the fruiting body was as shown in Figure 2. The first flush of fruiting body production was obtained on day 14 after the inoculation of the spawn. The higher production of RSM was obtained on day 5 of $23.5 \mathrm{~kg}$ and decreased until day 14 of $4.7 \mathrm{~kg}$. The second peak of production was obtained on day 16 of $8.1 \mathrm{~kg}$ and the lowest production on day 22 of $1.7 \mathrm{~kg}$.

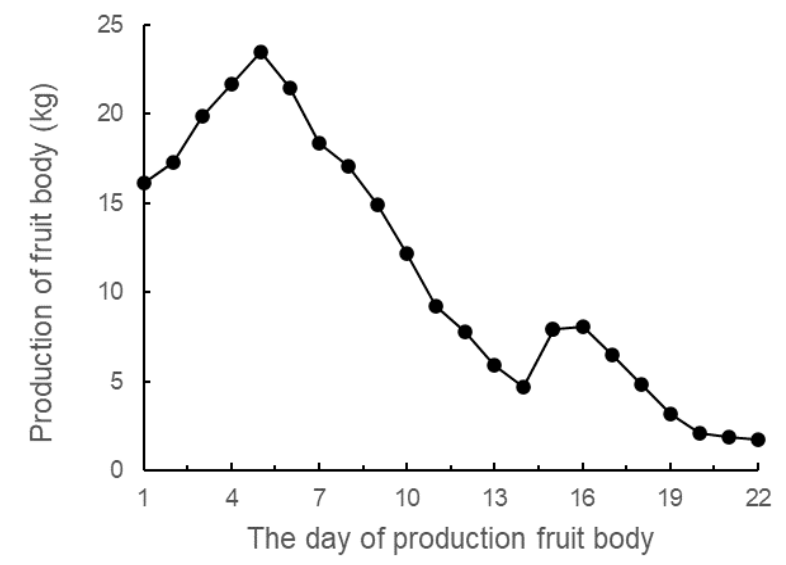

Figure 2. Day to day production of $V$. volvacea or rice straw mushroom (RSM)
The total production of RSM during one period of cultivation is $246.4 \mathrm{~kg}$. The Biological efficiency during bioconversion of rice straw to produce RSM which was calculated from the ratio of the weight of the fresh fruiting body $(\mathrm{g})$ per fresh weight of substrate $(\mathrm{g})$ was $24.64 \%$. After the mushrooms had been picked, the fruit body of RSM was cleaned up and put in the basket. Eventually, the packages were ready to be transported to the fresh market (Figure 1.e).

\subsection{Cultivation of P. ostreatus}

The genus Pleurotus has been intensely studied and cultivated in many different parts of the world. In this study, the species of $P$. ostreatus was cultivated in a polypropylene bag and called a bag $\log$. The growth of $P$. ostreatus was determined by measuring mycelial extension. The spawned baglogs was incubated at room temperature, $29-31{ }^{\circ} \mathrm{C}$ and humidity $7-85 \%$ (Figure $3 . a$.). The growing mycelium was measure on $5,10,15$, and 30 days of incubation. After mycelium covers the surface of the baglogs, they were transferred to the production room (Figure 4).

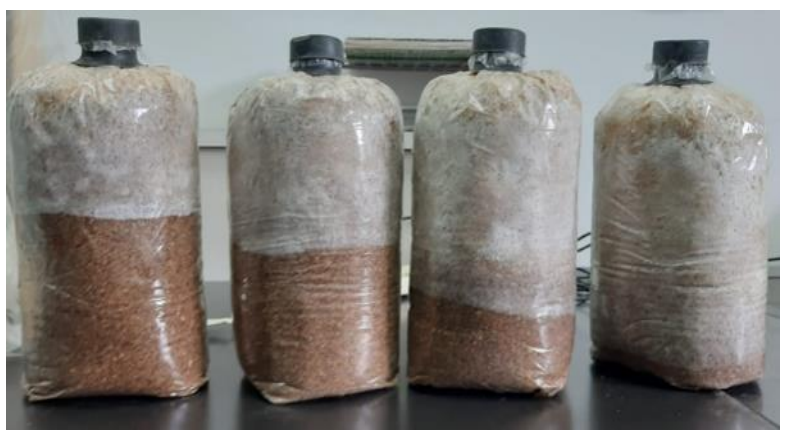

Figure 4. The growth of $P$. ostreatus was determined by measuring the length of mycelia growth on the baglog. Left to right: $5,10,15$, and 30 days of incubation time period

The temperature and humidity were maintained at 29$31{ }^{\circ} \mathrm{C}$ and $80-90 \%$ to arrange the suitable condition for the fruiting body production (Figure 3.b.). The first production of fruiting body usually was harvested approximately 3-5 days later.

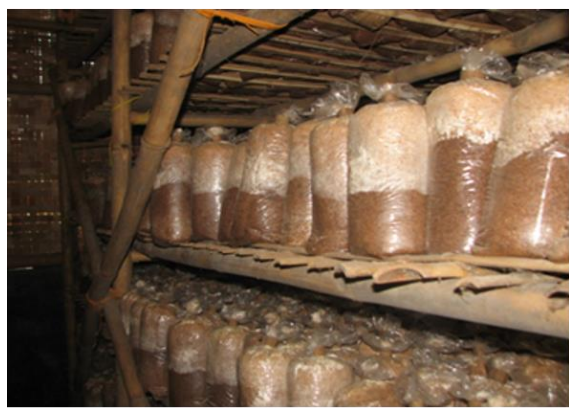

(a)

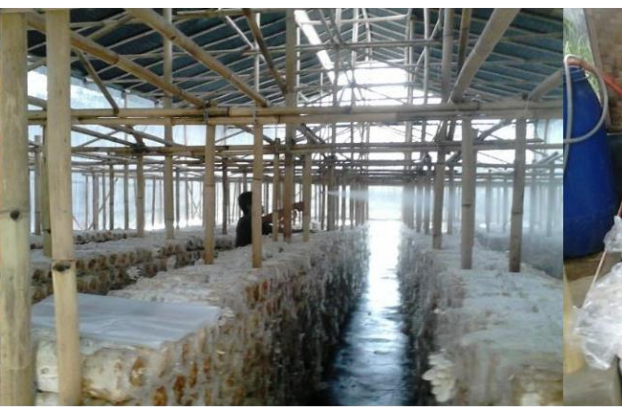

(b)

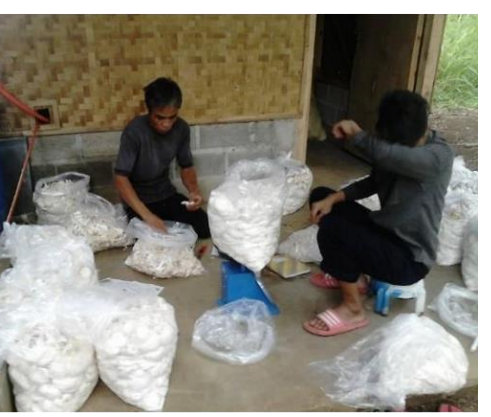

(c)

Figure 3. Cultivation of $P$. ostreatus: (a) the spawned baglogs were incubated in the incubation room for growing the mycelia; (b) manual fogging to maintain the temperature and humidity in mushroom house; (c) packing the $P$. ostreatus before selling them to the market 
In one production cycle, there were three or four flushes of the fruiting body of P. ostreatus with 5-7 days of interval. However, the fourth flush was ignored because of its small size. The BE of $P$. ostreatus using sawdust as substrate was $32.5 \%$. It means that using 1000 $\mathrm{g}$ of baglog can produce $325 \mathrm{~g}$ of fruiting body. Environmental factors affect the fruiting body development of mushrooms. Khan and Chandra, 2017[14] reported that those main factors are light, $\mathrm{CO}_{2}$ concentration, humidity, temperature, and components of growing substrate.

Maintenance of the microclimate in the mushroom house is very important for production of $P$. ostreatus. Fogging is a common program for optimizing the microclimate of the mushroom house that really depends on the weather (Figure 3.b). The temperature and humidity of mushroom house during cultivation of $P$. ostreatus was shown in Tabel 2. The fruiting body harvesting of $P$. ostreatus was to pick them up, sort and clean them up. Plastic packages with $5 \mathrm{~kg}$ of fruiting bodies were sold in the market (Figure 3.c).

Table 2. Average minimum and maximum temperature and relative humidity measured during cultivation period of P. ostreatus

\begin{tabular}{lcc}
\hline Parameters & Outdoor & Indoor \\
\hline $\begin{array}{l}\text { Maximum } \\
\text { temperature }\left({ }^{\circ} \mathrm{C}\right)\end{array}$ & 31 & 29 \\
\hline $\begin{array}{l}\text { Minimum } \\
\text { temperature }\left({ }^{\circ} \mathrm{C}\right)\end{array}$ & 29 & 27 \\
\hline $\begin{array}{l}\text { Relative humidity } \\
(\%)\end{array}$ & 78 & 93 \\
\hline
\end{tabular}

Mushrooms provide an impressive nutritional value, like protein, essential amino acids and fiber, poor fat, with an excellent important fatty acids content. Mushrooms contain about $19-35 \%$ of protein, and normally, it is lower compared to most animal meats, but it is higher than vegetables, fruits and other foods [15]. The presence of protein in mushrooms composed of all nine essential amino acids (EAAs). In contrast to most other plant-based protein options which are typically missing one or more EAAs. Moreover, mushrooms have a high branched-chain amino acid (BCAA) composition, which is usually only found in animal-based protein sources. The quality of protein is determined by several parameters such as the in vitro protein digestibility (IVPD), protein digestibility corrected amino acid score (PDCAAS), and essential amino acid index (EAAI).

The coronavirus 19 (Covid-19) pandemics likely still continues to spread with no estimation when it will be ended. Millions of people have been infected worldwide. This pandemic affects the development growth of the economy as well as food security throughout the world, including Indonesia. Basically, the pattern of food consumption of most Indonesians is far from ideal. They particularly consume more carbohydrates than protein, fruits, or vegetables. Furthermore, there is also an increasing trend to consume instant food, either in rural and urban areas. Proteins provided by mushrooms have attracted many people as an alternative protein source instead of animal protein.

However, at this moment the consumption of protein provided by mushrooms in Indonesia is still lower than that of the other countries. The consumption rate of mushrooms in Indonesia is relatively low $(0.18$ per capita/year) in comparison to France of 4.5, Japan 3.5, Australia 3.0 and Canada 2.8 respectively. For that reason, a campaign to introduce that edible mushroom is the super food during covid 19 is still needed.

\section{CONCLUSION}

Bioconversion of lignocellulosic agriculture waste to an edible mushroom can be utilized for efficient cultivation of mushrooms, particularly $V$. volvacea and $P$. ostreatus. It is the best method to solve the problem of agricultural waste. The simple technology in this method is easy to apply in a rural area. Furthermore, an edible mushroom as the high-quality food is produced and targeted during this bioconversion method. In the case of bioconversion of rice straw by RSM, from $1000 \mathrm{~kg}$ of rice straw can produce $250 \mathrm{~kg}$ of RSM. On the other hand, bioconversion of sawdust by P. ostreatus, from $100 \mathrm{~kg}$ of sawdust can produce $35.5 \mathrm{~kg}$ of $P$. ostreatus.

\section{AUTHORS' CONTRIBUTIONS}

Iwan Saskiawan and Atik Retnowati contributed to the design and implementation of the research, to the analysis of the results and to the writing of the manuscript.

\section{ACKNOWLEDGMENTS}

We thank the Research Centre for Biology, Indonesian Institute of Sciences for providing the funding and complete facilities during this research.

\section{REFERENCES}

[1] U. Simha, and Vijayalakshmi. Sustainable Waste Management by Growing Mushroom (Pleurotus florida) on Anaerobically Digested Waste and Agro Residues. International Journal of Engineering Research \& Technology (IJERT). 2012. Vol 1(5). https://www.researchgate.net/publication/3349896 32

[2] P.G. Miles and S.T. Chang. Mushroom Biology: Concise Basics and Current Developments. Singapore: World Scientific, 1997, pp. 194.

[3] J.B. Hagen. Five Kingdoms, More or Less: Robert Whittaker and the Broad Classification of Organisms. BioScience, 2012, Vol. 62, pp: 67-74, https://doi.org/10.1525/bio.2012.62.1.11 
[4] D. Hawksworth. The fungal dimension of biodiversity: magnitude, significance, and conservation. Mycological Research, 1991, 95(6):641-655, DOI:10.1016/S09537562(09)80810-1

[5] D. Hawksworth andR. Lücking. Fungal Diversity Revisited: 2.2 to 3.8 Million Species. Microbiology Spectrum, 2017, 5(4). DOI:10.1128/microbiolspec.FUNK-0052-2016

[6] A. Retnowati, A. Kusmawaty, I Apandi, A. Haryadi. Two newly recorded species of Agaricales (Basidiomycota) from Banggai Kepulauan, Sulawesi, Indonesia. Biodiversitas, 2020, Vol. 21 (12), pp: 5615-5621, DOI: 10.13057/biodiv/d211217

[7] I. Saskiawan. Bioconversion of rice straw to produce straw mushroom (Volvariella volvacea). Proceedings The 12th Sciences Council of Asia (SCA) Conference and International Symposium. 2012. pp. $405-413$

[8] I. Saskiawan, I. and N. Hasanah, 2018. Cultivation of Edible Mushroom. Technical Report of Biovillage Programme. (Budidaya Jamur Pangan, Laporan Teknik Kegiatan Biovillage) Cibinong, Indonesia: Research Center for Biotechnology LIPI (in Bahasa Indonesia)

[9] I. Saskiawan, N. Hasanah, and N. Shimomura. 2016. Cultivation of Pleurotus ostreatus using sorghumsupplemented spawn on various substrates. Mushroom Science and Biotechnology. 2016, Vol 23(4) pp: 179-182.

[10] H. Zikriyani, I. Saskiawan, and W.W. Mangunwardoyo. Utilization of Agricultural Waste for Cultivation of Paddy Straw Mushrooms (Volvariella volvacea (Bull.) Singer 1951). International Journal of Agricultural Technology, 2018 Vol. 14(5): 805-814. Available online http://www.ijat-aatsea.com

[11] L.D. Thang. Growing edible mushroom. Ho Chi Minh Agricultural Publisher, 2016, 242 p

[12] I.O. Fasidi. Studies on Volvariella esculenta (mass) singer: cultivation on agricultural wastes and proximate composition of stored mushrooms. Food Chemistry, 1966, Vol 55(2), pp:161-163

[13] M.K. Biswas and M. Layak. Techniques for increasing the biological efficiency of paddy straw mushroom (Volvariella volvacea) in eastern India. 2014. Food Science Technology, vol 2(4):52-57

[14] B.J. Akinyele and F.C. Adetuyi. Effect of agrowastes, $\mathrm{pH}$ and temperature variation on the growth of Volvariella volvacea. African Journal Biotechnology, 2005, Vol 4(12), pp:1390-1395

[15] F. Khan and R. Chandra. Effect of physicochemical factors on fruiting body formation in mushroom. International Journal of Pharmacy and Pharmaceutical Sciences. 2017, Vol 9 (10), pp: 3336

[16] V.L. Kohen, T.L. Nogueira, I.S. Salinas, F.R. Marin, C.S. Rivas, and A.R. Molina. Nutritional and Functional Properties of Edible Mushrooms: A Food with Promising Health Claims. Journal of Pharmacy and Nutrition Sciences. 2004, Vol. 4, pp; 187-189 